\title{
Management of Patients Using Oral Anticoagulant Agent in Dental Practice
}

\author{
(D) Özge DOGANAY, iD Türker YÜCESOY, iD Alper ALKAN
}

Bezmialem Vakıf University Faculty of Dentistry, Department of Oral and Maxillofacial Surgery, İstanbul, Turkey

\section{ABSTRACT}

An increasing number of patients in our country use oral anticoagulants for the prophylaxis and treatment of thromboembolic events. The cornerstone of these groups of agents is warfarin, a vitamin $\mathrm{K}$ antagonist, which has been the single alternative used by oral route for several years. However, due to warfarin's late onset and long lasting action and the intense interactions with food and drugs, newer oral anticoagulants have emerged in the market in recent years. Dabigatran, rivaroxaban and apixaban are the novel agents used in our country.

Those drugs should be regulated in the perioperative period when patients receiving oral anticoagulants are referred for dental interventions. The interruption of agents may result in lethal consequences of thromboembolic events, while continuing raises the risk of bleeding. This review outlines the various properties of the oral anticoagulants and the most recent recommendations and guidelines regarding the management of dental patients taking these medications.

Keywords: Warfarin, dental aproach, novel, bleeding risk, thromboembolism, dabigatran, rivaroxaban, apixaban

\section{Introduction}

Oral anticoagulant agents are used for the treatment of arterial and venous thromboembolism (VTE) or prophylaxis. Patients using these agents frequently refer to clinics for dental interventions. Withdrawing oral anticoagulants during the perioperative period increases the risk of thromboembolism and maintenance of them is associated with the risk of bleeding. Dentists should consider the risk of thromboembolism and bleeding under the guidance of a cardiologist and choose the most appropriate option among discontinuation, continuation or bridging.

Heart valve prosthesis, atrial fibrillation (AF) and VTE/pulmonary embolism history are the most important risk factors for thromboembolism. Thrombophilia tendency and some systemic diseases also increase the risk of thromboembolism (Table 1).

The risk of bleeding (no risk of bleeding, low or high risk of bleeding) is also affected by factors such as hypertension, liver and kidney failure, old age, predisposition to bleeding, and other drugs and alcohol use that increase bleeding

\section{Warfarin and Bridging}

The prototype of oral anticoagulant agents is warfarin, which is an antagonist of vitamin K-dependent factors (FII, FVII, FIX, FX). The therapeutic effect of warfarin is monitorized by prothrombin time and international normalized ratio (INR) (therapeutic level INR: 2.5-3.5 \pm 0.5 ). However, the effectiveness of the agent should be checked frequently, due to its interactions with food, differences of the patients in response to the drug and narrow therapeutic range of the drug $(1,2)$.

Discontinuation of warfarin during the perioperative period is not preferred in terms of risk of thromboembolism. Warfarin is continued or replaced by another anticoagulant agent. "Bridging" means replacing an agent with another drug that has similar effects. Since warfarin has a long half-life, it is necessary 
to interrupt taking warfarin 5 days prior to the preoperative period to reduce bleeding. Patients are exposed to the risk of thromboembolism in a large window as a result of slow reach to the therapeutic level when the drug is started again during the postoperative period. It is thought that discontinuation of warfarin for a while and bridging with another short-and fastacting agent (heparin derivatives) is both protective and reduces the risk of bleeding. It is aimed to eliminate the effect of heparin in the morning of surgery by skipping the morning dose and to maintain thromboembolism prophylaxis after homeostasis is achieved in postoperative period by re-starting heparin. Bridging is recommended in patients with high thromboembolism risk who will undergo interventions with major bleeding risk. In patients with moderate risk of thrombosis, patient-based decisions are made by taking into account the risk of bleeding (3).

Varfarin is most commonly bridged by low molecular weight heparin (LMWH). Since this method is generally preferred in patients at high risk of thromboembolism, it is recommended that heparin be administered in a therapeutic dose (Enoxaparin $2 \times 1 \mathrm{mg} / \mathrm{kg}$, therapeutic dose: $2 \times 80 \mathrm{mg}$ for a patient weighing $80 \mathrm{~kg}$, Clexane $2 \times 0.8 \mathrm{~mL}$ ). In the bridging protocol, warfarin is stopped 5 days before the surgery and LMWH is initiated 3 days before the surgery. INR follow-up is required to maintain a value of 1.4 or lower before the surgery. Patients should continue with LMWH for 5-7 days after the onset of warfarin in the postoperative period, which is necessary to achieve therapeutic INR level. After the decision is made that there is no risk of bleeding, 48-72 hours after major surgeries, and 24 hours after minor surgeries, LMWH is initiated. Warfarin is also initiated with the dose used in preoperative period, with LMWH and when INR reaches therapeutic level (2-3), LMWH is stopped (3).

Recent studies show that bridging with LMWH does not affect the frequency of thromboembolism but increases bleeding dramatically (3-5). When all studies are evaluated together, the rate of perioperative bleeding is $13 / 1$ with bridging and 5/1 without bridging (6). Although it is known that thromboembolic events may be more vital than bleeding, such a high risk of bleeding is also a major drawback.
Beyer-Westendorf et al. (7) reported that major surgery and bridging with LMWH were the factors that increased the risk of bleeding in perioperative period in the Dresden study on new generation oral anticoagulants (drugs were continued, stopped or bridged with LMWH). Douketis et al. (8) stopped warfarin in patients with AF with low risk of thromboembolism and treated one group with placebo and treated other group with $100 \mathrm{IU} / \mathrm{kg}$ dalteparin bridging treatment. The incidence of thromboembolism was found to be $0.3 \%$ and $0.4 \%$ in the groups, while the incidence of major and minor bleeding was significantly higher in the bridging group with dalteparin (8). The most common reason for the increase in bleeding with bridging was early onset of LMWH in postoperative period and not skipping the evening dose of LMWH which was given in therapeutic doses $(2 \times 1)$, in preoperative period (3).

\section{New Generation Oral Anticoagulant Agents}

In recent years, new-generation oral anticoagulant agents (NOACs), which are fast acting, have short half-life, have less drug and food interaction, have more predictable effects and do not need to be followed by laboratory tests, have been introduced. These are dabigatran, a direct thrombin inhibitor (Pradaxa, Boehringer Ingelheim, İstanbul, Turkey); rivaroxaban, a factor Xa inhibitor (Xarelto, Bayer, İstanbul, Turkey); and apixaban, a factor Xa inhibitor (Eliquis, Bristol Myers Squibb, İstanbul, Turkey). Features of NOACs are summarized in Table 2 (9-12).

Dabigatran (Pradaxa): It is a thrombin inhibitor and is often used in a dose of $2 \times 150 \mathrm{mg}$. Thrombin time (TT) and ecarin clotting time (ECT) are tests that measure the efficacy of dabigatran, and minimal prolongation is observed in activated partial thromboplastin time (aPTT). In the case of renal failure, its effect is prolonged and dose adjustment is required, since it is excreted from the kidney.

Rivaroxaban (Xarelto): It is a factor Xa inhibitor and is often used in a dose of $1 \times 15-20 \mathrm{mg}$. Its efficacy is measured with antifactor Xa level.

Table 1. Classification of thromboembolism risk

Risk Mechanical valve

Mitral valve prosthesis

High

Moderate

Low
Caged ball, tilting-disk aortic valve prosthesis

CVA/TIA $<6$ months

Aortic valve bioprosthesis and other risk factors (*)

Aortic valve bioprosthesis

Atrial fibrillation

CHADS $_{2}$ score 5-6

CVA/TIA $<3$ months

Rheumatic valvular disease

CHADS $_{2}$ score $3-4$

CHADS $_{2}$ score 1-2

No history of CVA/TIA
Venous thromboembolism

VTE $<3$ months

Severe thrombophilia (+)

VTE 3-12 months

Recurrent VTE

Active cancer

Mild thrombophilia

VTE $>12$ months without other risk factors

CVA: Cerebrovascular accident, TIA: Transient ischemic attack, $\mathrm{CHADS}_{2}$ score: A scoring scale to determine thromboembolism risk in atrial fibrillation. (C: Congestive heart failure, H: Hypertension, A: Age>75 years, D: Diabetes mellitus, S:Stroke-2 points), (*) Other risk factors: Congestive heart failure, hypertension, age>75 years, diabetes mellitus, AF, history of CVA/TIA, (+) Severe thrombophilia: Protein C and Protein S deficiency, antithrombin, anti-phospholipid antibodies, (\&) Hafif trombofili: Heterozigot faktör V Leiden, protrombin gen mutasyonu, VTE: Venous thromboembolism 
Apixaban (Eliquis): It is a factor $\mathrm{Xa}$ inhibitor and is often used in a dose of $2 \times 5 \mathrm{mg}$. Its efficacy is measured with anti-factor $\mathrm{Xa}$ level.

The most important disadvantage of NOACs is the problem faced in reversing their effects. While the effect of varfarin can be eliminated with proper doses of vitamin $\mathrm{K}$ and fresh frozen plasma infusion, idarucizumab which is the antidote of dabigatran, a NOAC, is not available in our country. Protrombin complex concentrate is recommended for bleeding due to these agents (10).

\section{Dental Management in Patients Using Oral Anticoagulants}

Dentists should determine the treatment approach by evaluating the risk of bleeding in dental interventions in patients using oral anticoagulants perioperatively. The risk of bleeding in dental procedures is classified in different ways in different sources $(1,2,13,14)$. Table 3 shows the classification of bleeding risk according to the guidelines of the Scottish Dental Clinical Effectiveness Programme (SDCEP) (1).

When the literature is examined, there are highly reliable studies searching the use of warfarin in dental interventions, but there are no evidence-based data for NOAC use. However, most studies support the idea of continuing anticoagulant treatment in patients undergoing outpatient dental surgery, including tooth extraction $(15,16)$

Dental interventions are usually evaluated in the group of operations with minor bleeding risk and in patients with INR level below 4, it is recommended to continue warfarin $(1,2,11,15-20)$. In patients with stable INR levels, the INR level obtained in the last 72 hours may be acceptable, but in patients with labil INR levels, the INR level obtained in the last 24 hours should be evaluated. If the patient's INR level is 4 or higher, the patient should be consulted to his/her physician and dental treatments should be postponed until the INR level falls below 4. For emergency treatment, the patient should be directed to an upper level dental treatment center.

Broekema et al. reported that dental procedures can be performed in patients using warfarin with INR level of 3.5 or lower (checked in the last 24 hours) without discontinuing treatment (20). These operations include simultaneous extraction of no more than 3 teeth, surgical removal of buried teeth, periodontal treatment, apical resection, abscess drainage or dentoalveolar surgery performed by placing up to 3 implants. It is recommended that the operations be performed atraumatically, that the

Table 2. Features of new generation oral anticoagulant agents

\begin{tabular}{l|l|l|l} 
& Dabigatran & Rivaroxaban & \multicolumn{1}{c}{ Apixaban } \\
\hline Implementation & PO, $2 \times 1$ & $\mathrm{PO}, 1 \times 1$ & PO, $2 \times 1$ \\
\hline $\begin{array}{l}\text { Peak affect } \\
\text { Half-life }\end{array}$ & $1-3 \mathrm{~h}$ & $2-4 \mathrm{~h}$ & $1-3 \mathrm{~h}$ \\
\hline Elimination & $12-14 \mathrm{~h}$ & $5-13 \mathrm{~h}$ & $8-15 \mathrm{~h}$ \\
\hline PT & $80 \%$ renal, 20\% feces & $65 \%$ renal, & $25 \%$ renal, $70 \%$ hepatic \\
\hline aPTT & $+/-$ & $35 \%$ hepatic & $+/-$ \\
\hline TT & $+/-$ & $+/-$ & $+/-$ \\
\hline Anti-Xa level & +++ & $+/-$ & - \\
\hline Antagonization & - & - & +++ \\
\hline PT: Prothrombin time, aPTT: Activated partial thromboplastin time, TT: Thrombin time, PCC: Prothrombin complex concantrate & 4 PCCs (Cofact)
\end{tabular}

\section{Table 3. Risk of postoperative bleeding in dental interventions}

Dental interventions that are not expected to cause bleeding

Local anesthesia (infiltration, intraligamenter, mental nerve block, inferior dental block or other regional nerve block)

Basic periodontal examination

Removal of supragingival plaque, stone and discoloration

Direct or indirect restorations in supragingival margin

Endodontic interventions

Prosthetic interventions

Ortodontic interventions
Dental interventions that may cause bleeding

Bleeding complication with low risk

Simple extractions (1-3 teeth)

Incision and intraoral drainage

Root surface straightening and subgingival curettage

Direct or indirect restorations in the subgingival margin
Bleeding complication with high risk

Complicated extractions (large wound surface or extraction of more than 3 teeth)

Interventions with flap removal:

-Elective surgical teeth extraction

-Periodontal surgery

-Preprosthetic surgery

-Periradicular surgery

-Surgical crown lengthening

-Dental implant surgery

-Gingival contouring

biopsy 
suction socket is sutured close to the mouth, that the patient is discharged after the bleeding is stopped and information is given and that the mouth is rinsed with 5\% tranexamic acid during the postoperative 5 days (20).

Recommendationson the use of newgeneration oral anticoagulants are based on clinical experience, pharmacodynamics, and expert opinions. According to the SDCEP (1), in patients taking NOACs with low risk of bleeding, dental treatment should be performed without discontinuation of the drug. Many national guidelines and reviews including expert opinions recommend that many attempts at dentistry should be made without discontinuing NOACs $(2,9-11,17-19,21-23)$. In this group of patients using NOACs, it is emphasized that there is no place to bridge with LMWH during the perioperative period $(18,19,24)$.

New-generation oral anticoagulant drugs are generally preferred in patients with lower risk of thrombosis (such as non-valvular $\mathrm{AF}$ ), so they can be discontinued when there is a need for more major surgery. Dabigatran and apixaban are stopped 12 hours before, whereas rivaroxaban is stopped 24 hours before a dental intervention with high risk of bleeding by skipping the dose on the morning of the intervention. Rivaroxaban should be started four hours after the bleeding is under control and dabigatran and apixaban could be initiated by giving the evening dose (25).

\section{Conclusion}

In conclusion, it is observed that there is no need to bridge with LMWH routinely in perioperative period in patients who are currently using oral anticoagulants and who will undergo dental intervention. In line with this data, we believe that a large number of dental interventions can be performed using local hemostatic precautions without stopping oral anticoagulants and warfarin.

\section{Authorship Contributions}

Concept: A.A., Ö.D., Design: Ö.D., T.Y., Literature Search: T.Y., Writing: Ö.D.

Peer-review: Externally peer-reviewed.

Conflict of Interest: No conflict of interest was declared by the authors.

Financial Disclosure: The authors declared that this study received no financial support.

\section{References}

1. http://www.sdcep.org.uk/wp-content/uploads/2015/09/SDCEPAnticoagulants-Guidance.pdf

2. http://www.sigwales.org/wp-content/uploads/dental-managementof-patients-taking-anticoagulant-drugs-outside-a-general-hospitalsetting.pdf

3. Siegal D, Yudin J, Kaatz S, Douketis JD, Lim W, Spyropoulos AC. Periprocedural heparin bridging in patients receiving vitamin $\mathrm{K}$ antagonists: systematic review and meta-analysis of bleeding and thromboembolic rates. Circulation 2012;126:1630-9.

4. Douketis JD, Healey JS, Brueckmann M, Eikelboom JW, Ezekowitz $\mathrm{MD}$, Fraessdorf $\mathrm{M}$, et al. Perioperative bridging anticoagulation during dabigatran or warfarin interruption among patients who had an elective surgery or procedure. Substudy of the RELY trial. Thromb Haemost 2015;113:625-32.

5. Steinberg BA, Peterson ED, Kim S, Thomas L, Gersh BJ, Fonarow GC, et al. Outcomes Registry for Better Informed Treatment of Atrial Fibrillation Investigators and Patients. Use and outcomes associated with bridging during anticoagulation interruptionsin patients with atrial fibrillation: findings from the Outcomes Registry for Better Informed Treatment of Atrial Fibrillation (ORBIT-AF). Circulation 2015;131:488-94.

6. Rechenmacher SJ, Fang JC. Bridging Anticoagulation: Primum Non Nocere. J Am Coll Cardiol 2015;66:1392-403.

7. Beyer-Westendorf J, Gelbricht V, Förster K, Ebertz F, Köhler C, Werth $S$, et al. Peri-interventional management of novel oral anticoagulants in daily care: results from the prospective Dresden NOAC registry. Eur Heart J 2014;35:1888-96.

8. Douketis JD, Spyropoulos AC, Kaatz S, Becker RC, Caprini JA, Dunn AS, et al. Perioperative Bridging Anticoagulation in Patients with Atrial Fibrillation. N Engl J Med 2015;373:823-33.

9. Firriolo FJ, Hupp WS. Beyond warfarin: the new generation of oral anticoagulants and their implicationsfor the management of dental patients. Oral Surg Oral Med Oral Pathol Oral Radiol 2012;113:43141.

10. Elad S, Marshall J, Meyerowitz C, Connolly G. Novel anticoagulants: general overview and practical considerations for dental practitioners. Oral Dis 2016;22:23-32.

11. Little JW. New oral anticoagulants: will they replace warfarin? Oral Surg Oral Med Oral Pathol Oral Radiol 2012;113:575-80.

12. Breuer G, Weiss DR, Ringwald J. 'New' direct oral anticoagulants in the perioperative setting. Curr Opin Anaesthesiol 2014;27:409-19.

13. Hong $\mathrm{CH}$ and Intekhab I. Anti-Thrombotic Therapy: Implications for Invasive Outpatient Procedures in Dentistry. J Blood Disorders Transf 2013, 4:6. http://dx.doi.org/10.4172/2155-9864.1000166

14. Mingarro-de-León A, Chaveli-López B. Alternative to oral dicoumarin anticoagulants: Considerations in dental care. J Clin Exp Dent 2013;5:e273-8.

15. Perry DJ, Noakes TJ, Helliwell PS; British Dental Society. Guidelines for the management of patients on oral anticoagulants requiring dental surgery. Br Dent J 2007;203:389-93.

16. Richards D. Guidelines for the management of patients who are taking oral anticoagulants and who require dental surgery. Evid Based Dent 2008;9:5-6.

17. O'Connell JE, Stassen LF. New oral anticoagulants and their implications for dental patients. J Ir Dent Assoc 2014;60:137-43.

18. Spyropoulos AC, Douketis JD, Gerotziafas G, Kaatz S, Ortel TL, Schulman S; Subcommittee on Control of Anticoagulation of the SSC of the ISTH. Periprocedural antithrombotic and bridging therapy: recommendations for standardized reporting in patients with arterial indications for chronic oral anticoagulant therapy. Thromb Haemost 2012;10:692-4.

19. Breik O, Tadros R, Devitt P. Thrombin inhibitors: surgical considerations and pharmacology. ANZ J Surg 2013;83:215-21. 
20. Broekema FI, van Minnen B, Jansma J, Bos RR. Risk of bleeding after dentoalveolar surgery in patients taking anticoagulants. $\mathrm{Br} \mathrm{J}$ Oral Maxillofac Surg 2014;52:e15-9.

21. Van Diermen DE, van der Waal I, Hoogstraten J. Management recommendations for invasive dental treatment in patients using oralantithrombotic medication, including novel oral anticoagulants. Oral Surg Oral Med Oral Pathol Oral Radiol 2013;116:709-16.

22. Costantinides F, Rizzo R, Pascazio L, Maglione M. Managing patients taking novel (NOAs) in dentistry: a discussion paper on clinical implications. BMC Oral Health 2016;28:16:5.
23. Heidbuchel H, Verhamme P, Alings M, Antz M, Diener HC, Hacke W, et al. Updated European Heart Rhythm Association practical guide on the use of non-vitamin- $\mathrm{K}$ antagonist anticoagulants in patients with non-valvular atrial fibrillation: Executive summary. Eur Heart J 2017;38:2137-49.

24. Turpie AG, Kreutz R, Llau J, Norrving B, Haas S. Management consensus guidance for the use of rivaroxaban--an oral, direct factorXa inhibitor. Thromb Haemost 2012;108:876-86.

25. Johnston S. An evidence summary of the management of patients taking direct oral anticoagulants (DOACs) undergoing dental surgery, Int J Oral Maxillofac Surg 2016;45:618-30. 